\title{
DETERMINATION OF YIELD AND ESSENTIAL OIL COMPOSITION OF DIFFERENT LEMON BALM (Melissa officinalis L.) GENOTYPES
}

\author{
Duran KATAR ${ }^{1 *}$, Nimet KATAR ${ }^{2}$, Dogan AYDIN ${ }^{2}$ \\ ${ }^{1}$ Eskisehir Osmangazi University, Faculty of Agriculture, Department of Field Crops, Eskisehir, TURKEY \\ ${ }^{2}$ Eskisehir Osmangazi University, Graduate School of Natural and Applied Sciences, Field Crops, \\ Eskisehir, TURKEY \\ *Corresponding author: durankatar6060@gmail.com
}

Received: 08.05.2020

\begin{abstract}
This study was conducted in 2015 and 2016 in Eskisehir Osmangazi University, Faculty of Agriculture, Field Crops Department experimental field. The aim of this study was to determine the performance of yield and quality of lemon balm (Melissa officinalis L.) populations obtained from the natural vegetations of different provinces of Turkey at ecological conditions of Eskisehir. The study was designed in the Randomized Complete Block Design with three replications. As plant materials, eleven populations gathered from Tokat-2 (Geyraz), Burdur, Bilecik, Ankara, Malatya, USA, Bursa, Germany, Tokat-1 (Erbaa), Tokat-3 (Resadiye) and Kutahya were used in the study. In the study, plant height, fresh herb yield, dry herb yield, dry leaf yield, essential oil content and essential oil yield values of genotypes were determined. The determined values varied between 34.22-55.38 cm, 17.66-29.18 $\mathrm{t} \mathrm{ha}^{-1}, 3.75-7.23 \mathrm{t} \mathrm{ha}^{-1}, 2.46-4.53 \mathrm{t} \mathrm{ha}^{-1}, 0.06-0.24 \%$ and 2.88-17.14 $1 \mathrm{ha}^{-1}$, respectively. GC/MS analyzes in lemon balm samples revealed that geranial, neral, $\beta$-caryophyllene and caryophyllene oxide were the main components in all of the samples.
\end{abstract}

Keywords: Different plant populations, essential oil content and composition, lemon balm, Melissa officinalis L., yield.

\section{INTRODUCTION}

Lemon balm (Melissa officinalis L.), one of the most important species belonging to Lamiaceae/Labiate family, is a perennial herbaceous medicinal and aromatic plant (Vaverková et al., 2012). The plant originates from Asia Minor, Southern Europe and the Southern parts of North America (Adinee et al., 2009). In addition, the plant is reported to be distributed in the natural flora of the countries in the Mediterranean basin (Mencherini et al., 2007). The use of the lemon balm to prevent or treat certain diseases in folk medicine goes back to ancient times (Zeybek, 1987; Kacar et al., 2010). Lemon balm has been used in traditional medicine as memory enhancement (Adinee et al., 2009), cardiotonic and respiratory disorders (Moradpour et al., 2017), antidepressant (Alina et al., 2016) and anxiolytic agent and has also used in the treatment of cardiovascular (Chwil et al., 2016), mental and central nervous system diseases (Ozyigit et al., 2016) and various cancers (Mencherini et al., 2007). Also, it is recommended that herb mixtures with lemon balm leaves have been used in animal feeding in rather than fodder antibiotics (Turhan, 2006).

It has been known as 'Ogul Otu' because it has been used in diarrhea treatment of children in Anatolian folk medicine (Ceylan, 1997; Saglam et al., 2004; Adinee et al., 2009). In addition, it is known that people living in the Mediterranean basin have been using lemon balm leaves to keep the new swarms of honeybees in the new hives for many years (Turhan, 2006). Until the sixteenth century in many countries of the world, lemon balm had been collected from natural flora and used in traditional medicine. But the cultivation of the plant has been started to be made in European countries since sixteenth century (Zeybek, 1987; Kacar et al., 2010).

There are three subspecies of the Melissa officinalis species (subsp. inodora Bornm., subsp. altissima Arcangeli, subsp. officinalis). Of these subspecies, only Melissa officinalis subsp. officinalis with lemon scent is used in the treatment and perfumery (Ceylan, 1997; Baytop, 1999). The other two subspecies are generally used in food preservation because of their antimicrobial properties (Baytop, 1999; Moradkhani et al., 2010; Dirmenci, 2012). The characteristic scent of lemon balm is due to the essential oil present in the plant. Although the main bioactive substance of the plant is essential oil, it also contains triterpenes/triterpenoids, flavonoids, tannins and phenolic acids (Moradpour et al., 2017). The characteristic fragrance of lemon balm is due to the essential oil it contains, and the volatile oil content varies between $0.01-0.39 \%$ under the influence of various factors 
such as genotype/geographical origin of the plant, changing environmental and climate conditions, part of the plant, stage of maturity and cultivation techniques (Stefanini et al., 2006; Mencherini et al., 2007; Katar and Gurbuz, 2008; Adinee et al., 2009; Telci et al., 2009; Kacar et al., 2010; Bahmani et al., 2016; Acikgoz and Kara, 2020). In European countries, the content of essential oils in breeding cultivars varies between 0.13$0.27 \%$. In dry leaves of the plant, this rate increases up to $0.39 \%$ (Saeb and Gholamrezaee, 2012; Abdellatif et al., 2014). The ratio of citral-a (neral), which is the most important component of essential oil, varies between 20$60 \%$. Another important component of the essential oil is citronellal. The sum of these two components constitutes about $70 \%$ of the essential oil (Saeb and Gholamrezaee, 2012; Moradpour et al., 2017). It also contains some citronellol, linalool and geraniol and triterpene acids, phenol carbon-acid and flavonglycosides. Lemon balm essential oil is an important raw material especially for perfume and cosmetic industries (Moradkhani et al., 2010). Effectiveness of medicinal plants depends upon chemical composition and amount of active constituents present in the species. Chemical composition of bioactive materials is affected by various factors such as geneticmakeup/genetic modifications in the plant, growing conditions, seasonal variation in date of harvest of plant material, environmental conditions, sunlight exposure, altitude and agrothecnic practices (Telci, 2005; Tarha et al., 2010; Bhardwaj et al., 2019).

As in many other countries lemon balm collected from the wild flora in Turkiye are used for different purposes. However, this application not only risks the plant's presence in the wild flora, but is also not commercially attractive as it does not provide standard raw materials in terms of quality and supply (Turhan, 2006). Therefore, the general approach is to turn to the cultivation of medicinal plants in sustainable agricultural systems. In order to cultivate medicinal and aromatic plants in field conditions, besides knowing the yield and quality potential of the plant to be used in cultivation, sufficient information about the ecological requirements, planting time, plant density, nutrient and water requirements of the plant is needed (Gerami et al., 2016). For lemon balm to be produced successfully in field conditions, it is necessary to obtain the plant propagation materials with high yield and quality standards.

The aim of this study was to determine the yield and quality performances of the wild populations of lemon balm in natural vegetation of different regions of our country under Eskisehir ecological conditions in comparison with some commercial/standard varieties.

\section{MATERIALS AND METHODS}

\section{Plant material}

In this research, 8 different populations (Tokat-2 (Geyraz), Burdur, Bilecik, Malatya, Bursa, Tokat-1 (Erbaa), Tokat-3 (Resadiye) and Kutahya collected from natural vegetation in different regions of Turkey and 3 standard genotypes (Ankara, Germany and USA) were used as plant material.

The taxonomic identification of the collected plant was confirmed at Herbarium of the Faculty of Science and Letters, Eskisehir Osmangazi University, Eskisehir, Turkey and a sample was deposited in the Herbarium of the same Faculty.

\section{Climatic Conditions}

The plant can grow well at temperature range 15 to 35 ${ }^{\circ} \mathrm{C}$ and needs well-distributed $500-600 \mathrm{~mm}$ of rainfall throughout the growing season, plantations in areas where this precipitation can't be taken should be irrigated (Turhan, 2006). While the total annual precipitation in Eskisehir in 2016 was close to the values of long years, the value of precipitation in 2015 was higher than the value of long years. This difference in total annual precipitation was due to the high rainfall $(151.1 \mathrm{~mm})$ received in June 2015. When the distribution of total precipitation of both years to months was analyzed, it was seen that higher precipitation was received in February, March, June and August in 2015 compared to the values of long years, whereas in 2016, it was observed that higher precipitation was received in January, March, August and September. When the mean temperature values of the years in which the study was conducted were examined, it was seen that the average values of 2015 and 2016 were close to each other, but slightly higher than the values of long years. When the mean temperatures of the months are analyzed comparatively, it was seen that the biggest deviation occurred in February. In 2016, the average temperature of February was found to be quite high compared to the average values of both 2015 and long years (Anonymous, 2016a).

\section{Soil Characteristics}

Soil at a depth of $30 \mathrm{~cm}$ was sampled before the experiment and subjected to a physicochemical analysis. As is known, the plant prefers well-drained and sandy loamy fertile soils with a pH of 5 to 7 (Turhan, 2006). The $\mathrm{pH}$ value of the soil in which the experiment was conducted varies between 7.44-8.06. This showed that the soil was suitable in terms of $\mathrm{pH}$ value (Sonmez, 2003). The organic matter content of the soil was insufficient and varied between 1.10-1.18 \% (Gunes et al., 1996). The available potassium and phosphorus levels were 2460$2530 \mathrm{~kg} \mathrm{ha}^{-1}$ and $200-291 \mathrm{~kg} \mathrm{ha}^{-1}$ and potassium content was low and the amount of phosphorus was high. The lime rate was $5.78-6.44 \%$ and the soil was at a medium level in terms of lime content (Sonmez, 2003). In addition, the soil salinity was $0.032-0.042 \%$ and the experimental field area had no salt problem (Anonymous, 2016b)

Plant materials used in the experiment were taken as 25 root divisions with a single shoot belonging to each of the 8 populations and these plants were planted in the trial field in 2014. Each of the 25 plants belonging to three other genotypes used in the experiment and propagated vegetatively were planted next to the other plants in the field. In this plantation, the plants were transplanted with 
$50 \mathrm{~cm}$ interrow spacings and $30 \mathrm{~cm}$ intrarow spacings. Cultural practices needed for the plants in the plantation to grow and develop had been made in 2014.

The study was carried out in 2015 and 2016 at the experimental fields of the department of field crops, Faculty of Agriculture, Eskisehir Osmangazi University using randomized complete block design with three replications. 8 populations Tokat-2 (Geyraz), Burdur, Bilecik, Malatya, Bursa, Tokat-1 (Erbaa), Tokat-3 (Resadiye) and Kutahya and 3 standard genotypes (Ankara, Germany and USA) were used in the study. Trial plots were established in 2015 by using the rooted divisions of clumps/the root divisions with a single shoot taken from the plants in the plantation that was laid out in 2014. There are 4 rows of plants in the trial plots, and the seedlings were transplanted with $50 \mathrm{~cm}$ interrow spacings and $20 \mathrm{~cm}$ intrarow spacings (Arabaci, 1989; Ceylan et al., 1994; Katar and Gurbuz, 2008). The plants were planted in the trial field on 11.06.2015. The area of each trial plot is $6 \mathrm{~m}^{2}(3 \mathrm{~m} \mathrm{x} 2 \mathrm{~m})$. When installing the trial plantation, a distance of $2 \mathrm{~m}$ between blocks was left. Lemon balm is sensitive particularly to water deficiency in the establishment year. For this reason, $100 \mathrm{~mm}$ (from June to October in 2015) and $200 \mathrm{~mm}$ (from April to October in 2016) of water, which did not meet with precipitation throughout the growing season, were given to the plants by drip irrigation method. While irrigations were made more frequently in the establishment year of the plantation, irrigations were carried out at intervals of 15-20 days in 2016. Fertilization at $50 \mathrm{~kg} \mathrm{~N}$ and $40 \mathrm{~kg}$ $\mathrm{P}_{2} \mathrm{O}_{5} \mathrm{ha}^{-1}$ were applied according to soil analysis at the time of bed formation in the establishment year of the plantation. In the second year (2016), $100 \mathrm{~kg}$ of $\mathrm{N} \mathrm{ha}^{-1}$ fertilizer was divided into two and the first half was applied in the second half of April, while the second half was applied immediately after the first harvest (Katar and Gurbuz, 2008). Weeds in lemon balm fields both by negatively affecting the growth and development of balm plants and also due to mixing into fresh or dried herbs during harvest reduce the yield and quality of the product. In order to eliminate the negative effect of weeds, the necessary weed control was carried out by mechanical methods considering the growth and development of weeds in the plantation. Ten plants were selected at random from each plot for determining the plant heights. The plants were cut once $(01.10 .2015)$ in the establishment year of the plantation. After the two side lines of each plot and one plant from the ends of each row were discarded, the remaining plants were cut at $5-10 \mathrm{~cm}$ above ground in the morning (10:00-11:00). In the second year, the plants were harvested twice. The first harvest was made at the beginning of blooming on 30.06.2016, while the second cut was made on 08.10.2016 (Toth et al. 2003; Katar and Gurbuz, 2008; Saeb and Gholamrezaee, 2012).

The fresh samples were immediately dried in oven drying at $35^{\circ} \mathrm{C}$ for 48 hours. The plant height, fresh herb yield, drug herb yield, fresh leaf yield, drug leaf yield, fresh leaf/fresh herb (\%) and essential oil content and yield were measured.

In order to determine the essential oil content, $100 \mathrm{~g}$ dry leaf samples in $1.0 \mathrm{I}$ water from each sample were extracted by hydro-distillation for 3 hours using Clevenger apparatus according to the standard procedure described in European Pharmacopoeia (Stainier, 1975) for determining the oil content (v/w, \%). Samples of essential oil obtained by water distillation were stored in refrigerator at $4^{\circ} \mathrm{C}$ until the composition analysis.

\section{GC-MS Analyses}

The essential oil compositions of the oil samples were analyzed by gas chromatography (Agilent 5975C) coupled to mass spectrometry (Agilent 5975C) using capillary column (HP Innowax Capillary; $60.0 \mathrm{~m}$ x $0.25 \mathrm{~mm}$ x 0.25 $\mu \mathrm{m})$. Helium was used as carrier gas at $0,8 \mathrm{ml} / \mathrm{min}$ flow rate. Essential oils were diluted 1:100 ratios with hexane to analyse its composition. GC-MS analysis was carried out at split mode (40:1). The samples injection volume was adjusted as $1 \mu \mathrm{l}$ and injection temperature as $250{ }^{\circ} \mathrm{C}$. The oven temperature was programmed as $60^{\circ} \mathrm{C}$ for 10 minutes, increased at $4^{\circ} \mathrm{C}$ minute ${ }^{-1}$ to $220^{\circ} \mathrm{C}$, and held at $220^{\circ} \mathrm{C}$ for 10 minutes. MS spectra were monitored between 35-450 amu and the ionization mode used was electronic impact at $70 \mathrm{eV}$. The relative percentage of the components was calculated from GC-MS peak areas and components were identified by WILEY, and OIL ADAMS libraries. The percentage ratios of the results were determined by using FID detector, the identification of the components were determined by using MS detector.

The data obtained from experiments were subjected to analysis of variance according to a Randomized Complete Block Design. The differences between the mean values were determined by the multiple comparison method (LSD) (Steel and Torrie, 1980). In the evaluation of the data, TARIST statistical package program was used.

\section{RESULTS AND DISCUSSION}

In the research, the values of plant height, fresh herb yield, dry herb yield, fresh leaf yield, essential oil content and essential oil yield were analyzed depending on different genotypes and years. Data on variance analysis results and data on averages were given in Table 1.

As can be seen in Table 1, years, genotypes and genotype by year interaction indicated high significant $(\mathrm{p}<0.01)$ difference in the plant height. As the average of genotypes, $35.81 \mathrm{~cm}$ plant height value was obtained in 2015, while in 2016, $43.52 \mathrm{~cm}$ plant height value was determined. Considering the mean values over two-year, plant height values varied between $34.01-55.38 \mathrm{~cm}$ in genotypes. The highest plant height value was obtained from the Tokat-2 genotype, while the lowest value was obtained from the Kutahya genotype, which is in the same group as the USA genotype. The average plant height value of the genotypes was determined as $39.67 \mathrm{~cm}$. 
Table 1. Values of the effects of different lemon balm genotypes on yield and yield components in 2015 and 2016.

\begin{tabular}{|c|c|c|c|c|c|c|}
\hline & \multicolumn{3}{|c|}{ Plant Height (cm) } & \multicolumn{3}{|c|}{ Fresh Herb Yield (t ha-1) } \\
\hline Genotypes & 2015 & 2016 & Mean & 2015 & 2016 & Mean \\
\hline 1 & 46.45 & 64.30 & $55.38 \mathrm{~A}$ & 10.87 & 24.44 & $17.66 \mathrm{E}$ \\
\hline 2 & 33.63 & 44.52 & $39.08 \mathrm{C}$ & 11.65 & 27.10 & 19.38 DE \\
\hline 3 & 31.00 & 38.72 & 34.86 DE & 12.17 & 39.71 & $25.94 \mathrm{AB}$ \\
\hline 4 & 40.97 & 50.42 & $45.69 \mathrm{~B}$ & 13.30 & 30.86 & 22.08 CD \\
\hline 5 & 37.87 & 36.62 & 37.24 CDE & 16.20 & 35.97 & $26.08 \mathrm{AB}$ \\
\hline 6 & 27.20 & 40.82 & 34.01 E & 16.65 & 32.37 & 24.51 BC \\
\hline 7 & 34.91 & 42.25 & 38.58 CD & 12.50 & 40.89 & $26.69 \mathrm{AB}$ \\
\hline 8 & 33.17 & 39.17 & 36.17 CDE & 14.44 & 33.06 & 23.75 BC \\
\hline 9 & 44.30 & 44.13 & $44.22 \mathrm{~B}$ & 15.95 & 39.11 & $27.53 \mathrm{AB}$ \\
\hline 10 & 35.07 & 38.73 & 36.90 CDE & 18.42 & 39.94 & $29.18 \mathrm{~A}$ \\
\hline 11 & 29.37 & 39.07 & $34.22 \mathrm{E}$ & 19.10 & 35.65 & $27.38 \mathrm{AB}$ \\
\hline Mean & $35.81 \mathrm{~B}$ & $43.52 \mathrm{~A}$ & & $14.66 \mathrm{~B}$ & $34.46 \mathrm{~A}$ & \\
\hline L.S.D.(\%): & \multicolumn{3}{|c|}{$\mathbf{Y}: 6.24 ; \mathbf{G}: 4.22 ; \mathbf{Y} \times \mathbf{G}: 5.96$} & \multicolumn{3}{|c|}{$\mathbf{Y}: 5.45 ; \mathbf{G}: 3.81 ; \mathbf{Y} \times \mathbf{G}: 5.38$} \\
\hline FValues: & \multicolumn{3}{|c|}{$\mathbf{Y}: 150.56^{* *} ; \mathbf{G}: 34.24 * * ; \mathbf{Y} \times \mathbf{G}: 6.52 * *$} & \multicolumn{3}{|c|}{$\mathbf{Y}: 1302.41 * * ; \mathbf{G}: 12.96 * * ; \mathbf{Y} \times \mathbf{G}: 6.04 * *$} \\
\hline C.V.(\%): & \multicolumn{3}{|c|}{20.44} & \multicolumn{3}{|c|}{$\mathbf{4 4 . 7 4}$} \\
\hline & \multicolumn{3}{|c|}{ Dry Herb Yield $\left(\mathrm{t} \mathrm{ha}^{-1}\right)$} & \multicolumn{3}{|c|}{ Dry Leaf Yield (t ha' $\left.{ }^{-1}\right)$} \\
\hline Genotypes & 2015 & 2016 & Mean & 2015 & 2016 & Mean \\
\hline 1 & 0.91 & 6.60 & $3.75 \mathrm{C}$ & 0.60 & 4.32 & $2.463 \mathrm{C}$ \\
\hline 2 & 0.97 & 9.23 & $5.10 \mathrm{BC}$ & 0.71 & 5.62 & $3.162 \mathrm{BC}$ \\
\hline 3 & 1.01 & 12.92 & $6.97 \mathrm{~A}$ & 0.69 & 6.82 & $3.753 \mathrm{AB}$ \\
\hline 4 & 1.11 & 10.38 & $5.75 \mathrm{AB}$ & 0.82 & 6.72 & $3.772 \mathrm{AB}$ \\
\hline 5 & 1.35 & 11.51 & $6.43 \mathrm{AB}$ & 1.03 & 5.76 & $3.395 \mathrm{~B}$ \\
\hline 6 & 1.39 & 10.54 & $5.96 \mathrm{AB}$ & 1.00 & 6.56 & $3.782 \mathrm{AB}$ \\
\hline 7 & 1.04 & 13.10 & $7.07 \mathrm{~A}$ & 0.74 & 6.74 & $3.737 \mathrm{AB}$ \\
\hline 8 & 1.20 & 11.32 & $6.26 \mathrm{AB}$ & 0.91 & 7.00 & $3.955 \mathrm{AB}$ \\
\hline 9 & 1.33 & 13.14 & $7.23 \mathrm{~A}$ & 0.81 & 8.00 & $4.402 \mathrm{~A}$ \\
\hline 10 & 1.53 & 12.20 & $6.87 \mathrm{~A}$ & 1.13 & 7.92 & $4.528 \mathrm{~A}$ \\
\hline 11 & 1.59 & 11.09 & $6.34 \mathrm{AB}$ & 1.15 & 6.76 & $3.955 \mathrm{AB}$ \\
\hline Mean & $1.22 \mathrm{~B}$ & $11.1 \mathrm{~A}$ & & $0.87 \mathrm{~B}$ & $6.57 \mathrm{~A}$ & \\
\hline L.S.D.(\%): & \multicolumn{3}{|c|}{$\mathbf{Y}: 1.29 ; \mathbf{G}: 1.66 ; \mathbf{Y} \times \mathbf{G}: \mathbf{2 . 3 4}$} & \multicolumn{3}{|c|}{ Y: $1.05 ; \mathbf{G}: 0.84 ; \mathbf{Y} \times \mathbf{G}: \mathbf{1 . 1 9}$} \\
\hline FValues: & \multicolumn{3}{|c|}{$\mathbf{Y}: 5746.70^{* *} ; \mathbf{G}: 5.54 * * ; \mathbf{Y} \times \mathbf{G}: 4.61 * *$} & \multicolumn{3}{|c|}{$\mathbf{Y}: 2900.84^{* * ;} \mathbf{G}: 6.70^{* * ;} \mathbf{Y} \times \mathbf{G}: 4.86^{* *}$} \\
\hline C.V.(\%): & \multicolumn{3}{|c|}{84.72} & \multicolumn{3}{|c|}{80.38} \\
\hline & \multicolumn{3}{|c|}{ Essential Oil Content (\%) } & \multicolumn{3}{|c|}{ Essential Oil Yield $\left(\mathrm{L} \mathrm{ha}^{-1}\right)$} \\
\hline Genotypes & 2015 & 2016 & Mean & 2015 & 2016 & Mean \\
\hline 1 & 0.09 & 0.07 & $0.08 \mathrm{~F}$ & 0.56 & 5.19 & $2.88 \mathrm{H}$ \\
\hline 2 & 0.08 & 0.09 & $0.08 \mathrm{~F}$ & 0.56 & 9.39 & $4.98 \mathrm{GH}$ \\
\hline 3 & 0.18 & 0.20 & 0.19 B & 1.25 & 27.60 & $14.43 \mathrm{AB}$ \\
\hline 4 & 0.08 & 0.16 & $0.12 \mathrm{DE}$ & 0.66 & 20.82 & 10.74 CDE \\
\hline 5 & 0.05 & 0.10 & 0.07 F & 0.48 & 12.29 & 6.39 FG \\
\hline 6 & 0.09 & 0.17 & 0.13 CDE & 0.90 & 19.28 & 10.09 DE \\
\hline 7 & 0.09 & 0.18 & 0.14 CD & 0.67 & 24.54 & 12.60 BCD \\
\hline 8 & 0.24 & 0.24 & $0.24 \mathrm{~A}$ & 2.21 & 32.07 & $17.14 \mathrm{~A}$ \\
\hline 9 & 0.06 & 0.07 & $0.06 \mathrm{~F}$ & 0.49 & 9.89 & 5.19 GH \\
\hline 10 & 0.10 & 0.12 & $0.11 \mathrm{E}$ & 1.13 & 16.00 & 8.57 EF \\
\hline 11 & 0.10 & 0.20 & $0.15 \mathrm{C}$ & 1.11 & 26.33 & 13.72 BC \\
\hline Mean & 0.11 B & $0.15 \mathrm{~A}$ & & 0.91 B & $18.49 \mathrm{~A}$ & \\
\hline L.S.D.(\%): & \multicolumn{3}{|c|}{ Y: $0.02 ; \mathbf{G : 0 . 0 2 ; Y \times G : 0 . 0 3}$} & \multicolumn{3}{|c|}{$\mathrm{Y}: 0.75 ; \mathbf{G}: 3.01 ; \mathrm{Y} \times \mathbf{G}: 4.26$} \\
\hline FValues: & $Y: 616$ & G: 83.7 & $; \mathbf{Y} \times \mathbf{G}: 14.23^{* *}$ & Y: 5399 & *; $\mathbf{G}: 33$. & $; \mathbf{Y} \times \mathbf{G}: 27.64 * *$ \\
\hline C.V. $(\%):$ & & $\mathbf{4 8 . 0}$ & & & 110. & \\
\hline
\end{tabular}

Different genotypes showed significant differences in yield values varied between 17.66-29.18 $t \quad \mathrm{ha}^{-1}$ in fresh herb yield in 2015 and 2016. While the fresh herb genotypes. The highest fresh herb yield was obtained yield was $14.66 \mathrm{t} \mathrm{ha}^{-1}$ in 2015, it was $34.46 \mathrm{t} \mathrm{ha}^{-1}$ in 2016. from Tokat-3 genotype, while the lowest value was Considering the mean values over two-year, fresh herb obtained from Tokat-2 genotype. 
Significant differences were detected between various genotypes in terms of dry herb yield in 2015 and 2016. While the highest dry herb yield was recorded as $1.59 \mathrm{t}$ ha ${ }^{1}$ in USA genotype in 2015, the highest value in 2016 was determined in Tokat-1 genotype with $13.14 \mathrm{t} \mathrm{ha}^{-1}$. Considering the mean values over two-year, dry herb yield values varied between $3.75-7.23 \mathrm{t} \mathrm{ha}^{-1}$ in various genotypes. The highest dry herb yield was recorded as $7.23 \mathrm{t} \mathrm{ha}^{-1}$ in Tokat-1 genotype. The average dry herb yield value of the genotypes was determined as $6.16 \mathrm{t} \mathrm{ha}^{-1}$.

When the data of genotypes were evaluated together; dry leaf yield was $0.87 \mathrm{t} \mathrm{ha}^{-1}$ in 2015 and $6.57 \mathrm{t} \mathrm{ha}^{-1}$ in 2016. While the highest dry leaf yield was determined as $1.15 \mathrm{t} \mathrm{ha}^{-1}$ in USA genotype in 2015 , the highest value in 2016 was recorded in Tokat-3 genotype with $7.92 \mathrm{t} \mathrm{ha}^{-1}$. Considering the mean values over two-year, the highest dry leaf yield was recorded as $4.53 \mathrm{t} \mathrm{ha}^{-1}$ in Tokat-1 genotype. The average dry herb yield value of the genotypes was determined as $6.16 \mathrm{t} \mathrm{ha}^{-1}$. But Tokat-1 genotype, which has the highest value, was statistically in the same group as all other genotypes except Tokat-2, Burdur and Malatya genotypes.

As it is known, the essential oil contents of medicinal and aromatic plants are strongly dependent on genetic components. The essential oil contents differ between different crops, between different species of the same genus, between different groups of the same species or sub-species, and between different accessions or cultivars (Reily, 2013; Mammadov, 2014). Essential oil is the most important secondary metabolite of lemon balm plant. For this reason, essential oil content has been considered as the most important criterion that determines the quality of the product (Turhan, 2006; Moradkhani et al., 2010). The average essential oil content of the samples harvested in 2015 was determined as $0.11 \%$. In 2016 , the average essential oil content of the samples was determined as $0.15 \%$. The highest essential oil contents in 2015, 2016 and mean values over two-year were found to be $0.24 \%$ in the Germany genotype. This can be explained by the fact that the German genotype is an improved variety and has more suitable genetic components in terms of essential oil content compared to other genotypes.

In aromatic plants, dry plant yield and essential oil content of plant material are effective on essential oil yield per unit area. Therefore, all of the factors affecting these two parameters also affect the yield of essential oil per unit area. Average essential oil yield was determined as $0.91 \mathrm{l} \mathrm{ha}^{-1}$ in 2015 . In the first year of plantation, the highest essential oil yield was taken from the Germany genotype as $2.211 \mathrm{ha}^{-1}$. This can be attributed to the fact that the essential oil rate of plant material, which is the Germany genotype, is significantly higher than that of other genotypes. In 2016, the mean of genotypes of essential oil yield was 18. $491 \mathrm{ha}^{-1}$. The highest essential oil yields in 2016 were obtained from the Germany genotype as $32.07 \mathrm{l} \mathrm{ha}^{-1}$. Considering the mean values over two-year, the highest essential oil yield was recorded as $17.14 \mathrm{l} \mathrm{ha}^{-1}$ in the Germany genotype. When the mean values over two-year are taken into consideration, Bilecik and Bursa genotypes, which are among the local genotypes of our country, come to the fore in terms of essential oil yield.

In the first year of cultivation of perennial medicinal aromatic plants, the plants show a weaker growth and development compared to the following years (Turhan, 2006; Bruni and Sacchetti, 2009). As a result of this situation, no harvest can be made in the first year, or a very low yield can be achieved even if harvest is done (Moradkhani et al., 2010; Sharafzadeh et al., 2011). The fact that our values of 2016 are higher than the values of 2015 can be explained by the fact that 2015 is the establishment year of the plantation. In addition, it should not be overlooked that the climate conditions, which vary depending on the years, are also effective in the formation of the difference between the years.

The differences among the yield values of different lemon balm genotypes used in the study can be attributed to the genetic makeup differences of the genotypes (Baser et al., 2004; Adinee et al., 2009; Saeb and Gholamrezaee, 2012; Tansi et al., 2015, Katar et al., 2019). The values of the yield and yield components obtained from this study are in parallel with some literature values in general (Ceylan et al., 1994; Katar and Gurbuz, 2008; Adinee et al., 2009; Kacar et al., 2010; Ozyigit et al., 2016).

In the GC/MS analysis of essential oil samples of 2016, 18 different chemical components were determined. These 18 different components made up 93.71-99.98\% of essential oil samples. Geranial, neral, caryophyllene oxide, $\beta$-caryophyllene and 8-hydroxyneomenthol were identified as the main components of lemon balm essential oil. The proportions of these main components changed depending on the genetic components of the plant materials (Table 2).

The highest geranial rate $(37.64 \%)$ was detected in Tokat-1, while the lowest rate was found in Malatya genotype with $15.45 \%$. Among plant genotypes, the neral contents varied between $9.78-24.65 \%$ and the highest rate was determined in Tokat-1 genotype, while the lowest rate was obtained from Malatya genotype. Caryophyllene oxide ratios varied between $4.29-24.31 \%$ and the highest rate was determined in Bilecik genotype while the lowest rate was obtained from Burdur genotype. In essential oil samples, the highest $\beta$-Caryophyllene ratio was determined in Ankara genotype $(13.55 \%)$, while the lowest rate was in Tokat-3 genotype $(4.07 \%)$. In essential oil samples, the range of 8-Hydroxyneomenthol ratio was very wide, and it was determined that it varied between $0.84-15.50 \%$ depending on genotypes (Table 2 ). 
Table 2. Essential oil composition of lemon balm in 2016 (as a means of two cutting).

\begin{tabular}{|c|c|c|c|c|c|c|c|c|c|c|c|}
\hline \multirow[b]{2}{*}{ Composition } & \multicolumn{11}{|c|}{ Genotypes } \\
\hline & Tokat-2 & Burdur & Bilecik & Ankara & Malatya & Kutahya & Bursa & Germany & Tokat-1 & Tokat-3 & USA \\
\hline 1-Octen-3-ol & 1.32 & 1.30 & 1.76 & 1.31 & 1.20 & 1.36 & 1.48 & 1.19 & 0.86 & 1.29 & 1.78 \\
\hline Citronellal & 6.03 & 9.15 & 3.05 & 12.18 & 25.02 & 17.63 & 6.35 & 6.37 & 5.76 & 9.17 & 2.26 \\
\hline$\alpha$-Copaene & 1.76 & 0.88 & 1.06 & 1.07 & 1.39 & 0.53 & 0.80 & 0.86 & 0.57 & 0.67 & 0.75 \\
\hline Trans-Chrysanthemal & 0.50 & 0.77 & 0.48 & 0.51 & 0.55 & 0.60 & 0.73 & 0.58 & 0.62 & 0.48 & 0.52 \\
\hline$\beta$-Bourbonene & 0.43 & 1.51 & 1.22 & 0.94 & 0.73 & 0.14 & 0.91 & 0.87 & 0.90 & 1.28 & 0.90 \\
\hline Linalool & 1.48 & 1.71 & 2.44 & 1.84 & 0.97 & 2.30 & 0.84 & 0.46 & 1.88 & 1.10 & 1.07 \\
\hline Methyl citronellate & 2.29 & 0.71 & 1.32 & 1.23 & 1.60 & 1.95 & 1.43 & 0.48 & 0.48 & 0.78 & 0.47 \\
\hline$\beta$-Caryophyllene & 6.48 & 7.74 & 9.68 & 13.55 & 13.45 & 4.40 & 9.27 & 7.96 & 6.99 & 4.07 & 8.89 \\
\hline$\alpha$-Humulene & 0.59 & 1.19 & 1.06 & 1.23 & 1.17 & 0.35 & 0.90 & 0.78 & 0.63 & 0.43 & 0.97 \\
\hline Neral & 18.57 & 24.00 & 15.39 & 14.30 & 9.78 & 18.08 & 22.53 & 23.09 & 24.65 & 18.77 & 20.08 \\
\hline Methyl nerolate & 0.75 & 0.78 & 0.76 & 0.83 & 0.60 & 0.94 & 0.85 & 0.68 & 0.77 & 0.59 & 1.08 \\
\hline Geranial & 27.35 & 35.80 & 24.07 & 23.01 & 15.45 & 29.40 & 33.53 & 35.07 & 37.64 & 28.70 & 31.30 \\
\hline Geranyl acetate & 0.66 & 1.86 & 1.52 & 0.59 & 0.41 & 0.77 & 0.77 & 2.02 & 0.70 & 0.90 & 0.55 \\
\hline Caryophyllene oxide & 14.42 & 4.29 & 24.31 & 14.30 & 13.56 & 6.30 & 10.81 & 12.30 & 10.13 & 20.62 & 15.98 \\
\hline Humulene epoxide-II & 0.55 & 0.68 & 1.25 & 0.81 & 0.81 & 0.30 & 0.56 & 0.63 & 0.49 & 1.06 & 0.87 \\
\hline 8-Hydroxyneomenthol & 15.50 & 2.45 & 3.22 & 9.41 & 5.00 & 13.81 & 2.77 & 1.27 & 0.84 & 3.92 & 2.51 \\
\hline$\alpha$-Cadinol & 0.39 & 0.93 & 0.86 & 1.26 & 1.13 & - & 1.35 & 1.19 & 0.78 & 0.43 & 1.40 \\
\hline $\begin{array}{l}\text { 14-Hydroxy-9-Epi- } \\
\text { Caryophyllene }\end{array}$ & 0.93 & 1.10 & 1.40 & 1.17 & 0.94 & 1.11 & 1.34 & 1.08 & 1.01 & 2.07 & 2.58 \\
\hline Unidentified & 0.02 & 3.20 & 5.19 & 0.50 & 6.29 & 0.06 & 2.81 & 3.15 & 4.34 & 3.71 & 6.09 \\
\hline Total & 100.00 & 100.00 & 100.00 & 100.00 & 100.00 & 100.00 & 100.00 & 100.00 & 100.00 & 100.00 & 100.00 \\
\hline
\end{tabular}

The amount of plant metabolites is strongly influenced by the genetic makeup of the plant and environmental factors (Adinee et al., 2009; Moradkhani et al., 2010; Reily, 2013). The metabolite composition of plants is primarily under the influence of the genotype (Bhardwaj et al., 2019). However, environmental factors such as light, temperature, humidity, soil type, fertilizer application, damage caused by microorganisms and insects, stress caused by UV radiation, heavy metals and pesticides change the metabolite composition of plants (Hounsome et al., 2008; Bahmani et al., 2016). The differences in the chemical composition of essential oils detected in lemon balm samples of different genotypes studied can be explained by the genotypic differences of the plant materials. It was stated in the codex that the minimum essential oil ratio should be $0.05 \%$ and the main components of the essential oil should be geranial, neral and citronellal (Ceylan, 1997). When the studied materials are evaluated in terms of essential oil content and composition, it is seen that all of the materials have values above the minimum values specified in the codex.

\section{CONCLUSION}

Although some yield was obtained in 2015, the year of establishment of the plantation, it would not be correct to make a comment considering the values of the first year. Considering the values of 2016, Tokat-1, Tokat-3 and Bilecik populations and Germany and USA genotypes can be recommended for dry leaf production in Eskisehir ecological conditions. If lemon balm essential oil production is determined as the target, it may be suggested to use the Bilecik population and Germany genotype as plant material for our region. Because they were the genotypes in which the highest essential oil yields were obtained among the plant materials. Bilecik population and Germany genotype also have a composition suitable for essential oil main components, and the total ratio of geranial, neral, $\beta$-caryophyllene and caryophyllene oxide components ranged from 73.45 to $78.42 \%$.

\section{ACKNOWLEDGEMENTS}

This study was supported by Scientific Research Projects Commission of Eskisehir Osmangazi University (Project no: 2014-647).

\section{LITERATURE CITED}

Abdellatif, F., H. Boudjella, A. Zitouni and A. Hassani. 2014. Chemical Composition and Antimicrobial Activity of the Essential Oil from Leaves of Algerian Melissa officinalis L. EXCLI Journal 13:772-781.

Acikgoz, M.A. and S.M. Kara. 2020. Morphogenetic, Ontogenetic and Diurnal Variability in Content and Constituents of Bitter Fennel (Foeniculum vulgare Miller var. vulgare) Essential Oil. KSU J. Agric. Nat. 23 (1): $127-$ 134. DOI: $10.18016 /$ ksutarimdoga.vi.596542.

Adinee, J., K. Piri and O. Karami. 2009. Essential Oil Composition of Lemon Balm (Melissa officinalis L.) Leaves Grown in Hamadan Province, Iran. Medicinal and Aromatic Plant Science and Biotechnology 3(Special Issue 1): 58-60. Global Science Books.

Alina, V.R., C. Muresan, S. Muste, V. Muresan, G. Petrut and A.E. Muresan. 2016. A Comprehensive Review About Therapeutic Qualities of Essential Oil Lemon Balm (Melissa officinalis L.). Hop and Medicinal Plants 1-2:16-23.

Anonymous, 2016a. Data were taken from Eskisehir Regional Meteorological Service.

Anonymous, 2016b. The analyze was carried out in Eskisehir Osmangazi University, Faculty of Agriculture, Soil Analysis Laboratory.

Arabaci, O. 1989. Research on Yield and Ontogenetic Variability in Some Parfum Plants (Lavandula angustifolia Mill., Melissa officinalis L., Salvia sclarea L.). Master Thesis. Bornova-Izmir (in Turkish). 
Bahmani, K., D.A. Izadi, D.F. Alfekaiki and M. Sticklen. 2016. Phytochemical Diversity of Fennel Landraces from Various Growth Types and Origins. Agronomy Research 14(5): 1530-1547.

Baser, K.H.C., T. Ozek, N. Kirimer and G. Tumen. 2004. A comparative study of the essential oil of wild and cultivated Satureja hortensis L. Journal of Essential Oil Research 16(5): 422-424.

Baytop, T. 1999. Treatment with plants in Turkey (Past and Present). s: 307. Addition Second Edition, Istanbul University Publications, ISBN:975-420-021-1 (in Turkish).

Bhardwaj, S., S. Rashmi and V. Parcha. 2019. Effect of Seasonal Variation on Chemical Composition and Physicochemical Properties of Hedychium spicatum Rhizomes Essential Oil. Journal of Essential Oil Bearing Plants DOI: 10.1080/0972060X.2019.1703828

Bruni, R. and G. Sacchetti. 2009. Factors Affecting Polyphenol Biosynthesis in Wild and Field Grown St. John's Wort (Hypericum perforatum L. Hypericaceae/Guttiferae). Molecules 14: 682-725. DOI:10.3390/molecules14020682.

Ceylan, A. 1997. Medical Plants-II. (Essential Oil Plants). Ege University Faculty of Agriculture Publications No: 481 (in Turkish).

Ceylan, A., E. Bayram and N. Ozay. 1994. Melissa officinalis L. Research on agronomic and technological features of (Lemon balm). Turkish Journal of Agriculture \& Forestry 18(2):125-130 (in Turkish).

Chwil, M., R. Nurzyńska-Wierdak, S. Chwil, R. Matraszek and J. Neugebauerová. 2016. Histochemistry and Micromorphological Diversity of Glandular Trichomes in Melissa officinalis L. Leaf Epidermis. Acta Sci. Pol. Hortorum Cultus 15(3):153-172.

Dirmenci, T. 2012. Melissa L. in A. Guner (ed.) Turkey Plant List (Vascular Plants) Book. ANG Foundation, Istanbul (in Turkish).

Gerami, F., P.R. Moghaddam, R. Ghorbani and A. Hassani. 2016. Effects of irrigation intervals and organic manure on morphological traits, essential oil content and yield of oregano (Origanum vulgare L.). Anais da Academia Brasileira de Ciências 88(4): 2375-2385.

Gunes, A., A. Inal and M. Alpaslan. 1996. Effect of Salinity on Stomal Resistance, Proline, and Mineral Composition of Pepper. Journal of Plant Nutrition 19(2): 389-396.

Hounsome, N., B. Hounsome, D. Tomos and G. Edwards-Jones. 2008. Plant Metabolites and Nutritional Quality of Vegetables. Journal of Food Science 73(4):48-65.

Kacar, O., E. Goksu and N. Azkan. 2010. Effect of Different Plant Densities on Some Agricultural Characteristics in Lemon Balm (Melissa officinalis L.) Cultivation. Journal of Uludag University Faculty of Agriculture 24: 59-71 (in Turkish).

Katar, D. and B. Gurbuz. 2008. Effect of Different Plant Density and Nitrogen Doses on Drug Leaf Yield and Some Properties in Lemon balm (Melissa officinalis L.). Journal of Agricultural Sciences 14(1):78-81 (in Turkish).

Katar, N., D. Katar, R. Temel, S. Karakurt, I. Bolatkiran, E. Yildiz and A. Soltanbeigi. 2019. The effect of different harvest dates on the yield and quality properties of rosemary Rosmarinus officinalis L. plant. Biological Diversity and Conservation 12(3):7-13. DOI: 10.5505/biodicon.2019.29292.

Mammadov, R. 2014. Secondary Metabolites in Seed Plants. Nobel Academic Publishing, Document No:841, Ankara (in Turkish).

Mencherini, T., P. Picerno, C. Scesa and R. Aquino. 2007. Triterpene, antioxidant, and antimicrobial compounds from
Melissa officinalis. Journal of Natural Products 70: 18891894.

Moradkhani, H., E. Sargsyan, H. Bibak, B. Naseri, M. SadatHosseini, A. Fayazi-Barjin and H. Meftahizade. 2010. Melissa officinalis L., a valuable medicine plant: A review. Journal of Medicinal Plants Research 4(25): 2753-2759.

Moradpour, M., S.H. Ghoran and J. Asghari. 2017. Phytochemical investigation of Melissa officinalis L. flowers from Northern part of Iran (Kelardasht). Journal of Medicinal Plants Studies 5(3): 176-181.

Ozyigit, Y., E. Ucar, B. Tutuncu, I. Indibi and K. Turgut. 2016. The Effect of Different Nitrogen Doses on Yield and Some Yield Components of Melissa officinalis subsp. L. altissima (Sibthr. et Smith) Arcang. Turk J. Agric. Res. 3: 139-144. DOI: $10.19159 /$ tutad.79496.

Reily, K. 2013. On farm and fresh produce management (Part II, p:198-234). in B.K. Tiwari, Brunton, N.P. and Brennan, C.S. (ed.) Handbook of Plant Food Phytochemicals Sources, Stability and Extraction, ISBN 978-1-4443-3810-2 (hardback: alk. Paper), this edition first published by John Wiley \& Sons, Ltd., The Atrium, Southern Gate, Chichester, West Sussex, PO19 8SQ, UK.

Saeb, K. and S. Gholamrezaee. 2012. Variation of essential oil composition of Melissa officinalis L. leaves during different stages of plant growth. Asian Pacific Journal of Tropical Biomedicine 547-549. DOI:10.1016/S2221-1691(12)602718.

Saglam, C., I. Atakisi, H. Turhan, F. Arslanoglu and F. Onemli. 2004. Effect of propagation method, plant density, and age on lemon balm (Melissa officinalis) herb and oil yield. New Zealand Journal of Crop and Horticultural Science 32: 419423.

Sharafzadeh, S., O. Alizadeh and M. Vaki. 2011. Effect of Nitrogen Sources and Levels on Essential Oil Components of Thymus vulgaris L. Australian Journal of Basic and Applied Sciences 5(10): 885-889.

Sonmez, B. 2003. Turkey Aridity Control Guide, Ministry of Agriculture Soil and Fertilizer Institute of Research Publications, Technical Publications No: 33, Ankara (in Turkish).

Stainier, C. 1975. Role and functions of the European Pharmacopoeia. Ann Ist Super Sanita. 11(3-4): 211-219.

Steel, R.G.D. and J.H. Torrie. 1980. Principles and Procedures of Statistics. McGaw-Hill Book Company, Inc. N.Y.

Stefanini, M.B., L.C. Ming, O.C.M. Margues, R. Facanali, M.A.A. Meireles, L.S. Moura, J.A. Marchese and L.A. Sousa. 2006. Essential Oil Constituents of Different Organs of Fennel (Foeniculum vulgare var. vulgare). The medicinal Journal of Medicinal Plants 8: 193-198.

Tansi, L.S., S. Karaman, O. Toncer and S. Gedik. 2015. The Effects of Plant Density and Year on Yield of Purple Coneflower (Echinacea purpurea (L.) Moench. Turk J. Field Crops. 20(2): 174-178. DOI:10.17557/tjfc.68776.

Tarha, S., I. Telci, M.T. Tuncay and H. Polatci. 2010. Product quality and energy consumption when drying peppermint by rotary drum dryer. Industrial Crops \& Products 32(3): 420427.

Telci, I. 2005. Determination of appropriate shape heights in (Ocimum basilicum L.) genotypes. Gaziosmanpasa University Journal of Faculty of Agriculture 22(2): 77-83 (in Turkish).

Telci, I., I. Demirtas and A. Sahin. 2009. Variation in Plant Properties and Essential Oil Composition of Sweet Fennel (Foeniculum vulgare Mill.) Fruits During Stages of Maturity. Industrial Crops and Products 30(1): 126-130.

Toth, J., M. Mrlianova, D. Tekelova and M. Korenova. 2003. Rosmarinic Acid an Important Phenolic Active Compound 
of Lemon Balm (Melissa officinalis L.). Acta Phacultatis Pharmaceuticae Universitatis Comenianae 139-144.

Turhan, H. 2006. Lemon balm (Chapter 23, p:390-399). in K.V. Peter (ed.) Handbook of herbs and spices. Volume 3. Woodhead Publishing ISBN-10: 1-84569-171-7 (e-book). Woodhead Publishing Limited Cambridge, England.

Vaverková, S., I. Mistríková and P. Farka. 2012. Qualitative properties of Melissa officinalis after the application of Rastim 30 DKV. Botanica SERBICA 36(2):81-84.

Zeybek, N. 1987. Drugs exported from İzmir. V. Herbal Medicine Raw Materials Meeting Proceedings Book, pp: 5954, Ankara (in Turkish). 